\title{
Influence of Process Parameters on Structure and Mechanical Properties of Joints produced by Electromagnetic Forming and Friction Stir Welding
}

\author{
P. Barreiro ${ }^{1, a}$, V. Schulze $e^{1, b}$ and D. Löhe $e^{1, c}$ \\ ${ }^{1}$ Institute of Materials Science and Engineering I, University of Karlsruhe, \\ Kaiserstr. 12, Karlsruhe 76131, Germany \\ apablo.barreiro@iwk1.uni-karlsruhe.de, bvolker.schulze@iwk1.uni-karlsruhe.de, \\ cdetlef.loehe @iwk1.uni-karlsruhe.de
}

Keywords: Electromagnetic forming, friction stir welding, joining.

\begin{abstract}
Electromagnetic compression of tubular profiles with high electrical conductivity is an innovative joining process for lightweight structures. The components are joint using pulsed magnetic fields which apply radial pressures of up to $200 \mathrm{MPa}$ to tubular work pieces causing a symmetric reduction of the diameter with typical strain rates of about $10^{4} \mathrm{sec}^{-1}$. Since there is no contact between the components to be joined and the joining machine, any damage of component's surface can be avoided. Friction stir welding (FSW) is a relatively new solid state joining technique and has been extensively developed for aluminum, magnesium, copper and titanium alloys as well as steels. The primal advantages of the process in comparison to conventional fusion welding are better mechanical properties, low residual stresses and distortion, and reduced occurrence of defects. In the present article, the influence of process and material parameters on the joint's characteristics, material's microstructure and the mechanical properties of electromagnetic compressed joints and friction stir welds using reinforced aluminum profiles is analyzed. The strength of the joint is determined by tensile tests. Finally, possible improvements of both techniques are outlined.
\end{abstract}

\section{Introduction}

The reduction of weight of motor vehicle body components is commonly reached by using lightweight materials and manufacturing processes which allow for thin-walled structures. However an indispensable requirement is the availability of suited joining technologies which provide high strength joints for the main structure of vehicles. A vast experience is available for conventional joining processes like welding, screwing, clinching, riveting and gluing, but they require a complex preparation of the joint before the joining process is performed. Furthermore reinforced aluminum profiles cannot be joined by conventional fusion joining processes. Joining by forming processes like electromagnetic forming and the solid state joining technique friction stir welding offer possible resorts since they have the potential to fulfill the requirement of strength while allowing for the employment of reinforced aluminum profiles. Especially for structural components made of reinforced aluminum profiles both processes are suitable and of increasing industrial interest. Besides this, composite materials or two non-weldable alloys may be joined. However, the influence of process parameters on the performance of the joints is hardly investigated and deeper knowledge about this relationship is necessary to establish electromagnetic forming in industrial production [17]. Therefore, experimental investigations were made to evaluate both feasibility and capability of joining by both processes while varying the process parameters. 


\section{Process principle}

Electromagnetic forming. Electromagnetic forming is a high speed process using a pulsed magnetic field to form metals with high electrical conductivity such as aluminum. The energy density of a pulsed magnetic field is used for the contactless forming of a workpiece. Fig. 1 shows a schematic representation of the related joining process which concerns an electromagnetic tube compression. A tubular workpiece is placed coaxially inside a forming coil $L$. The coil is connected with a capacitor $C$ and a switch, forming a RLC circuit.
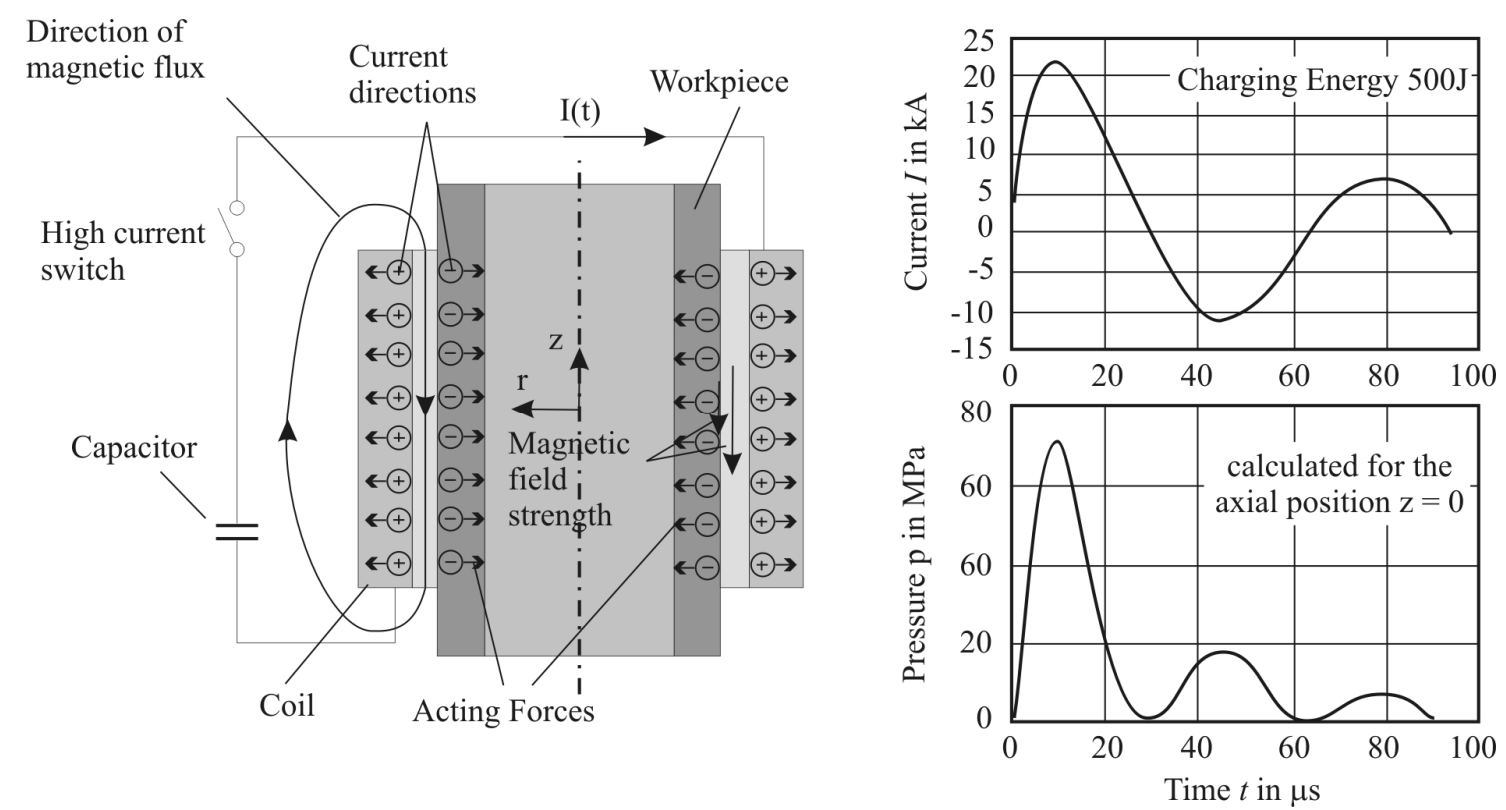

Fig. 1: Schematic representation of the process [1, 2].

After the capacitor bank has been charged with a desired energy it is suddenly discharged by closing a high current switch. The capacitor discharges a sinusoidal current which generates an alternating magnetic field in the coil. According to Lenz's law, an eddy current is induced in the workpiece flowing in the opposite direction to its cause. The current as well as the magnetic field penetrate the workpiece wall but are inhomogeneously distributed due to the skin effect. The resulting magnetic pressure $\mathrm{p}(\mathrm{t}, \mathrm{r}, \mathrm{z})$ is determined by the energy density of the magnetic field outside $H_{o}$ and inside $H_{i}$ of the workpiece and can be calculated on the basis of the measured coil current by [8]:

$$
p(r, t, z)=\frac{1}{2} \cdot \mu_{0} \cdot\left(H_{o}^{2}(r, t, z)-H_{i}^{2}(r, t, z)\right)
$$

The resulting pressure pulse acts in the radial direction on tube and tool coil (see Fig. 1). If the yield strength of the tube is exceeded, radial necking occurs. A joint produced by electromagnetic forming can be realized by compressing a tubular component on a mandrel. The force which takes effect on the mandrel's surface by the impact of the compressed tube leads to an elastic or elasticplastic deformation of the mandrel. After this, the corresponding elastic recovery of mandrel and tube proceeds. If a full relaxation of the mandrel is prevented by the tube, a permanent pressure in radial direction is established. The load, which the joints can transmit, strongly depends on the process parameters. Of these, the charging energy and initial gap between components are the most important ones as they yield to different impact velocities of the components to be joint [8-12].

Friction stir welding. Friction Stir Welding is a solid state joining process, in which a cylindrical shouldered tool with a counterclockwise threaded pin is rotated at a constant speed $(n)$ and inserted with a force $(F)$ into the adjacent material of the two pieces of material. The pin's length is slightly 
less than the weld depth required and the tool shoulder should be in intimate contact with the work surface. Frictional heat is created between the wear resistant pin and the two work pieces, which are butted together and clamped onto a backing bar. The materials to be joined soften due to the generated heat, without reaching the melting point, and allow the pin to traverse along the joint with a certain feed $(v)$. As the tool moves between the plates, the material is plasticized by the frictional heat at the front of the rotating pin and transported to the back. The joining of both plates is facilitated by severe plastic deformation in the solid state involving dynamic recrystallization of the base material [13-16]. Fig. 1 shows a schematic representation of the welding process.

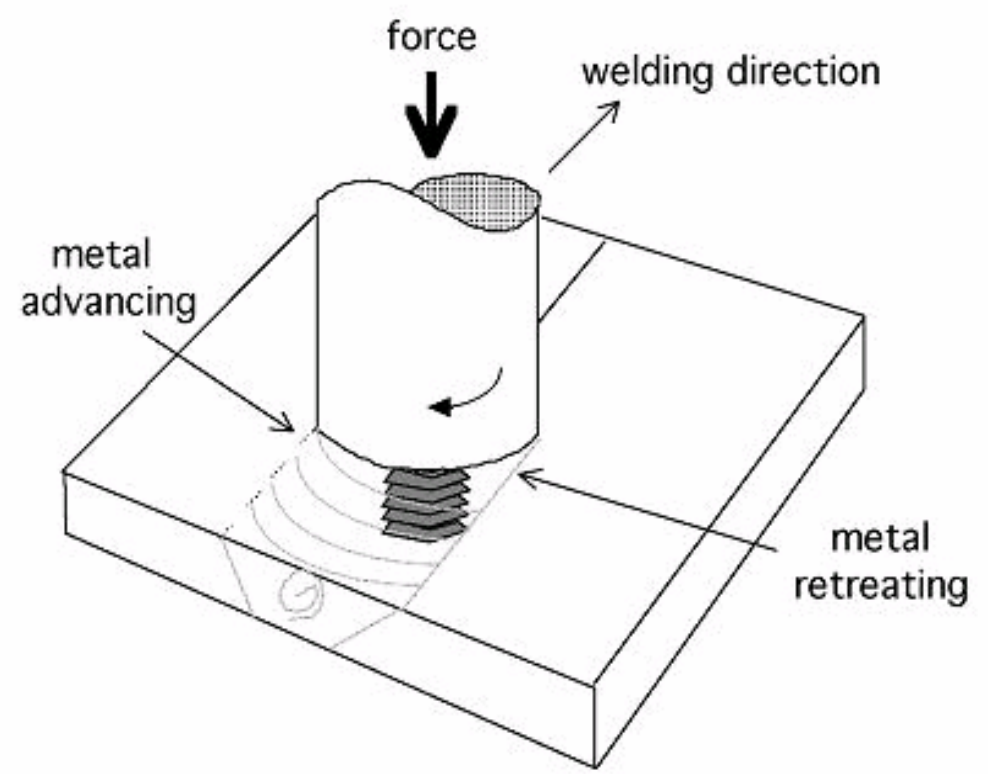

Fig. 2: Schematic representation of the friction stir welding process [17].

Several load components act on the welding tool during the joining process. An axial force is necessary to keep the correct vertical position of the tool relative to the materials surface. The lateral movement of the tool is accomplished by a force acting in the welding direction. Finally a clockwise torque is required to rotate the tool [13-16].

One of the most important advantages of FSW is the absence of the typical welding defects like porosity, solidification and liquation cracks. In general, FSW was found to produce a low concentration of defects and is very tolerant to parameter's and material's variations [13-16].

\section{Materials and testing method}

Force fit joints. For the present experimental investigations aluminum tubes were electromagnetically compressed on mandrels at the Institute of Forming Technology and Lightweight Construction, University of Dortmund (Germany). The material of both joint components was AA6060. The outer diameter of the tube was $20 \mathrm{~mm}$ with a wall thickness of $1 \mathrm{~mm}$. In addition the gap between tube and mandrel was $1.2 \mathrm{~mm}$. Fig. 3 shows a scheme of a test tube deformed by electromagnetic compression. The joining process was made with charging energies of $1.1 \mathrm{~kJ}$ and $1.5 \mathrm{~kJ}$. 


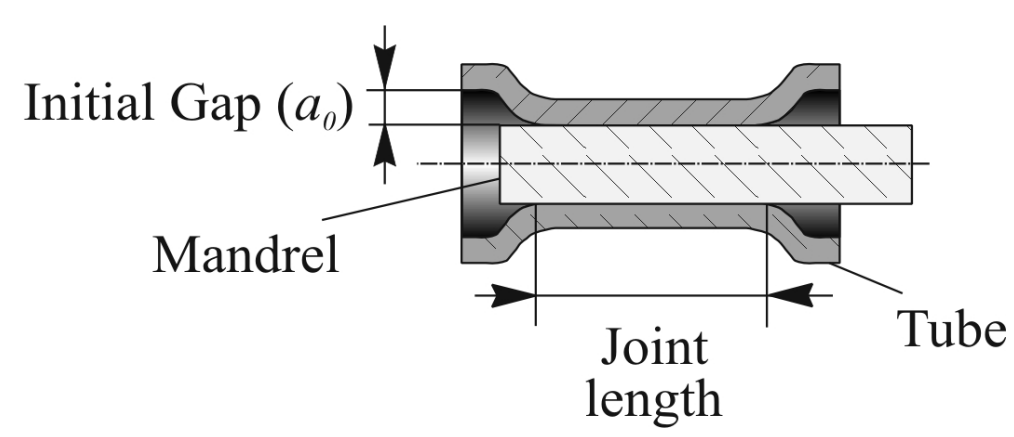

Fig. 3: Schematic representation of a test tube.

In order to analyze the influence of the mandrel's surface on the mechanical properties of the joint, the surface topography was altered by shot peening. As shot media $\mathrm{Al}_{2} \mathrm{O}_{3}$ with a mean diameter of $20-30 \mu \mathrm{m}$ (EKR320) and glass beads with a mean diameter of 20 - $30 \mu \mathrm{m}$ (MJ550B) were used. In addition, the shot pressure was varied from 0.5 up to 1.5 bar. After that, the surface topography and the residual stresses after shot peening were determined in order to evaluate the effect of peening. The strength of the joints was determined by tensile tests using a universal testing machine Zwick 1478 with a maximum force of $200 \mathrm{kN}$. The crosshead velocity was $2 \mathrm{~mm} / \mathrm{min}$. The quantities measured were the force and the relative displacement of the tubular component.

In order to analyze the influence of the friction welding between the components to be joint during cyclic loading, several joints were cyclically preloaded and then tested by monotonously increasing loading. The cyclic preloads at swelling loads $\left(R=\sigma_{\min } / \sigma_{\max }=0\right)$ were carried out in a $63 \mathrm{kN}$ Instron (Fast-Track 8800) servo-hydraulic machine. The test frequency was $2 \mathrm{~Hz}$. The maximum load was varied from $2 \mathrm{kN}$ to $6 \mathrm{kN}$. The quantities measured were the force, the relative displacement of the tubular component, and the complete displacement of the test tube. The relative displacement of the tubular component was measured with a capacitive sensor (small measuring range with high resolution) and the complete displacement of the test tube was measured with an inductive sensor (large measuring range with low resolution). The experiments were stopped after 10,100 and 1000 cycles.

FSW welds. For the present work aluminum butt welds in with austenitic spring steel 1.4310 (with a diameter of $1 \mathrm{~mm}$ ) reinforced sheets of the alloy AA6060 were produced at the Institute for Machine Tools and Industrial Management of Technical University of Munich (Germany). The reinforced sheets had a thickness of $5 \mathrm{~mm}$ and a width of $55 \mathrm{~mm}$. Both sheets exhibited 5 steel reinforcing elements. During the welding process the feed $(v)$ was maintained constant by 150 $\mathrm{mm} / \mathrm{min}$, but the rotational speed $(n)$ was varied in 4 steps from 750 up to $1500 \mathrm{rpm}$. The welding process was carried out using two different pins with a length of $4.7 \mathrm{~mm}$, one with a diameter of 4 $\mathrm{mm}$ and the other with a diameter of $5 \mathrm{~mm}$. A piece of each sample was extracted in order to determine the welding seam's geometry and microstructure and the presence of welding defects (using micrographs).

In order to analyze the deformation behavior in tensile tests, two specimens were taken out of each welded sample. Each sample for tensile tests had two reinforcing elements. The weld seam was located in each case in the middle of the sample and was perpendicular to the test direction. The tensile tests were carried out in a $100 \mathrm{kN}$ Zwick machine with a crosshead velocity of $2 \mathrm{~mm} / \mathrm{min}$. Force and strain were measured.

\section{Experimental results}

Force fit joints. Fig. 4 left shows the correlation between peeing induced residual stresses in the mandrel and shot pressure for both shot media. The compressive residual stresses at the mandrel's surface are strongly increased by shot peening. This increase is stronger in case of glass beads 
compared to $\mathrm{Al}_{2} \mathrm{O}_{3}$ particles. The different impulses of the shot media at the same shot pressure are responsible for the higher plastic deformation of the mandrel's surface in case of glass beads. Fig. 4 right shows the correlation between roughness and shot pressure for both shot media. The roughness of the mandrel's surface is strongly increased by peening at small shot pressure. A further increase of the shot pressure results in decreasing surface roughness. The findings are almost identical for both shot media.
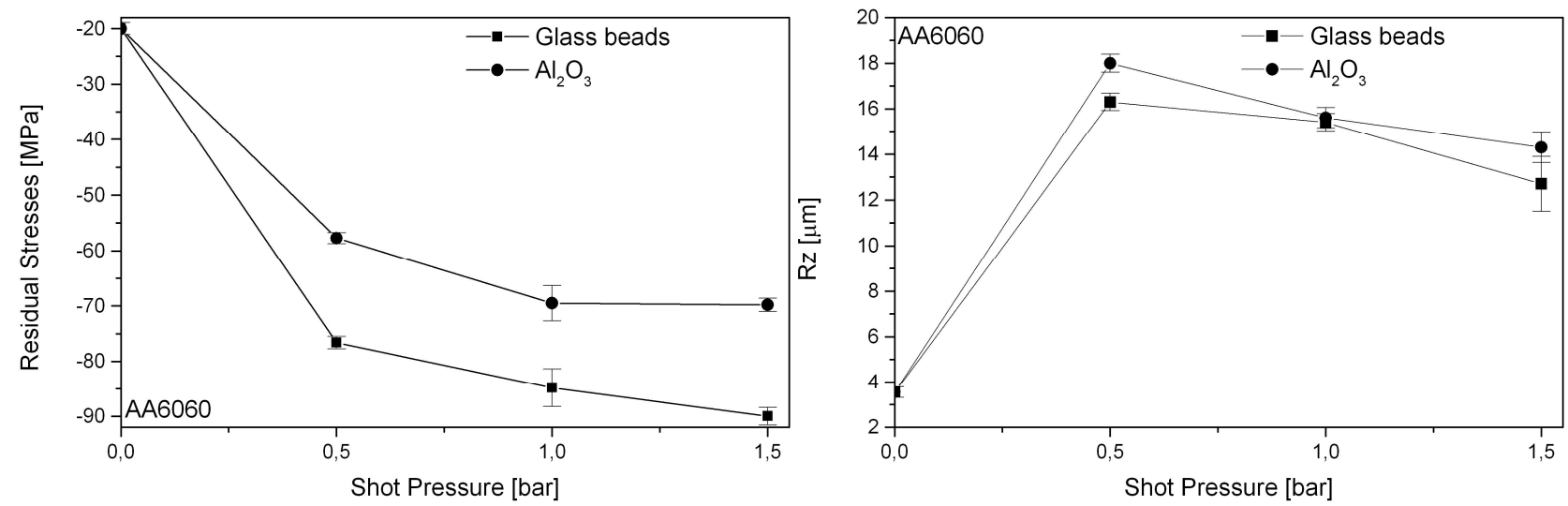

Fig. 4: Left: residual stresses at mandrel's surface after shot peening. Right: roughness of the mandrel after shot peening.

Inspite of the fact that the mandrel's roughness after shot peening by different shot pressures are similar, the surface's morphology shows substantial differences.

Fig. 5 shows scanning electron surface micrographs of two mandrels, which were shot peened with glass beads (left) and $\mathrm{Al}_{2} \mathrm{O}_{3}$ (right) at a shot pressure of 0.5 bar. The difference between highest and lowest point is similar in both cases. However the resulting surface is clearly smoother after shot peening with glass beads than with $\mathrm{A}_{2} \mathrm{O}_{3}$ particles.
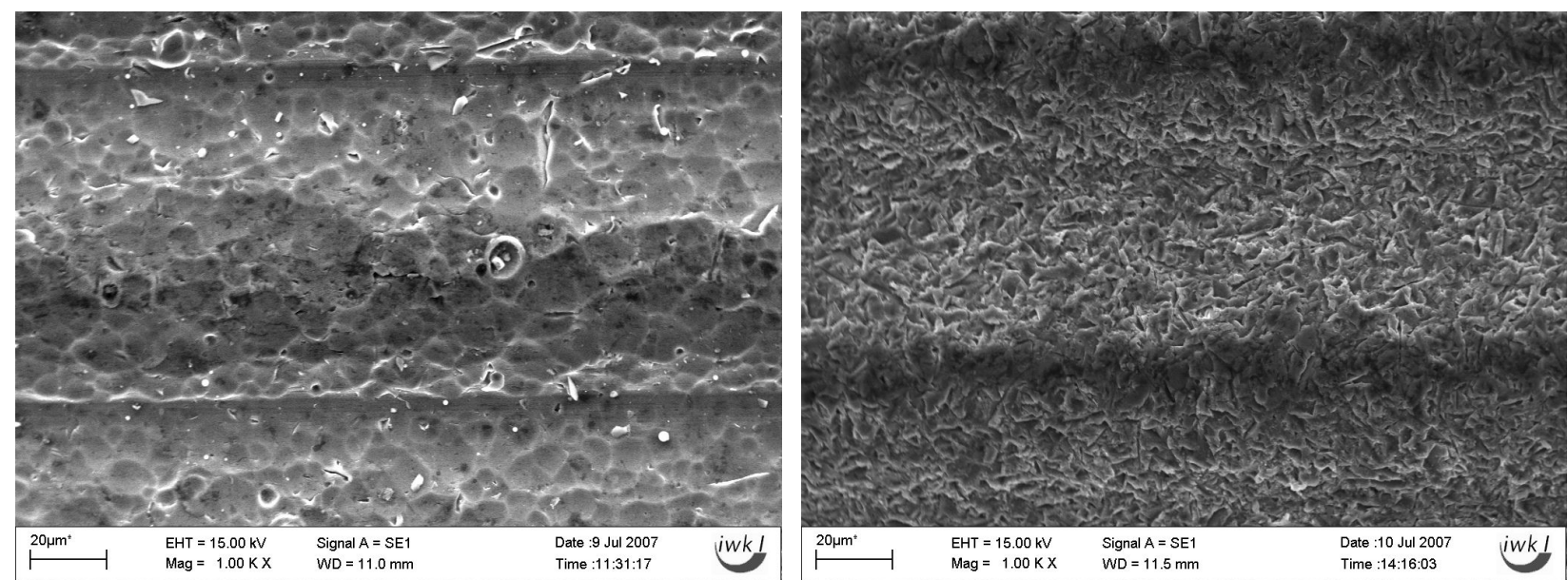

Fig. 5: Surface of shot peened mandrels (air pressure 0.5 bar). Left: glass beads, $20-30 \mu \mathrm{m}$. Right: $\mathrm{Al}_{2} \mathrm{O}_{3}, 20-30 \mu \mathrm{m}$.

As shown by Fig. 6, the pull-out force increases with increasing shot pressure for both shot media. However this increase is rather weak in case of joints whose mandrels were shot peened with glass beads. On the other hand, the reachable pull-out forces of joints, whose mandrels were shot peened with $\mathrm{Al}_{2} \mathrm{O}_{3}$ particles at pressures of 1 bar or more, are more than twice as high as of joints with unpeened mandrels [12]. 


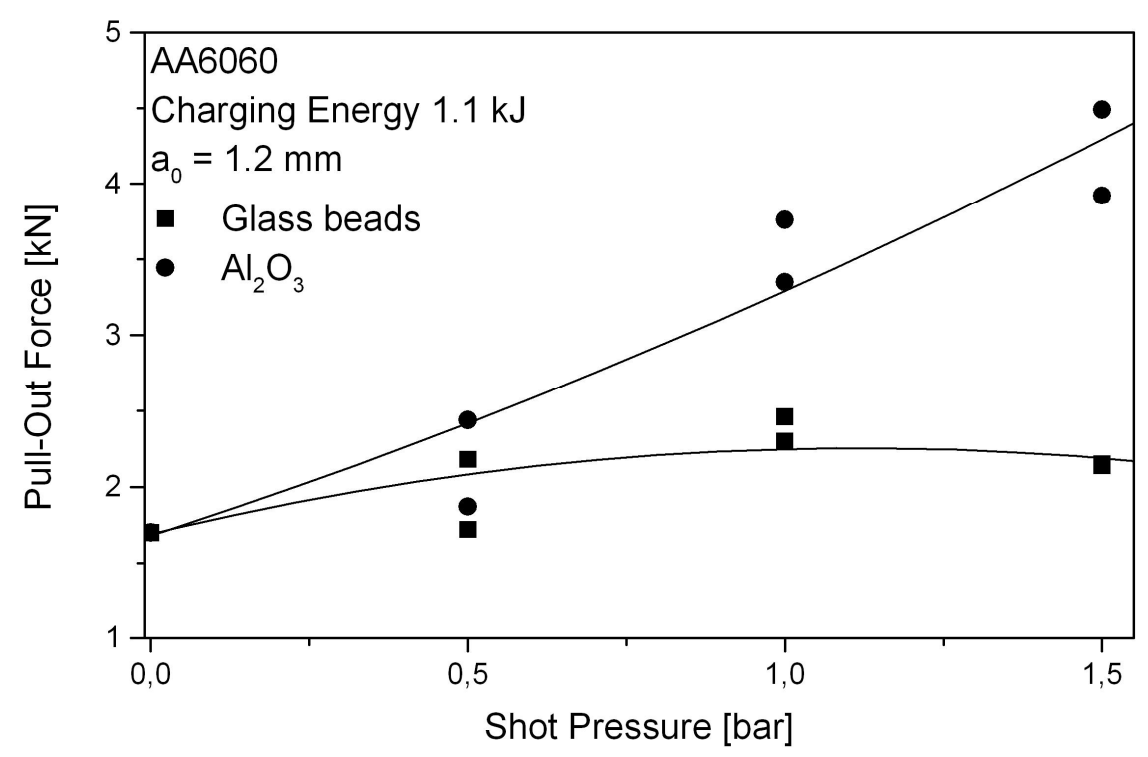

Fig. 6: Development of the pull-out force of joints with shot peened mandrels.

Joints whose mandrels were shot peened with $\mathrm{Al}_{2} \mathrm{O}_{3}$ particles partially exhibit form fit in the contact area between tube and mandrel due to the shot peening induced surface morphology and therefore show higher pull-out forces than joints with unpeened mandrels. This effect leads to pull-out-forces which would have needed a charging energy of $1.5 \mathrm{~kJ}$ in case of unpeened mandrels [12].

Fig. 7 shows as an example the force elongation curves of samples, which were cyclically preloaded with a maximum force of $4 \mathrm{kN}$ in comparison with an as joint sample. An increase of the achievable pull-out loads after the cyclic preload can be observed.

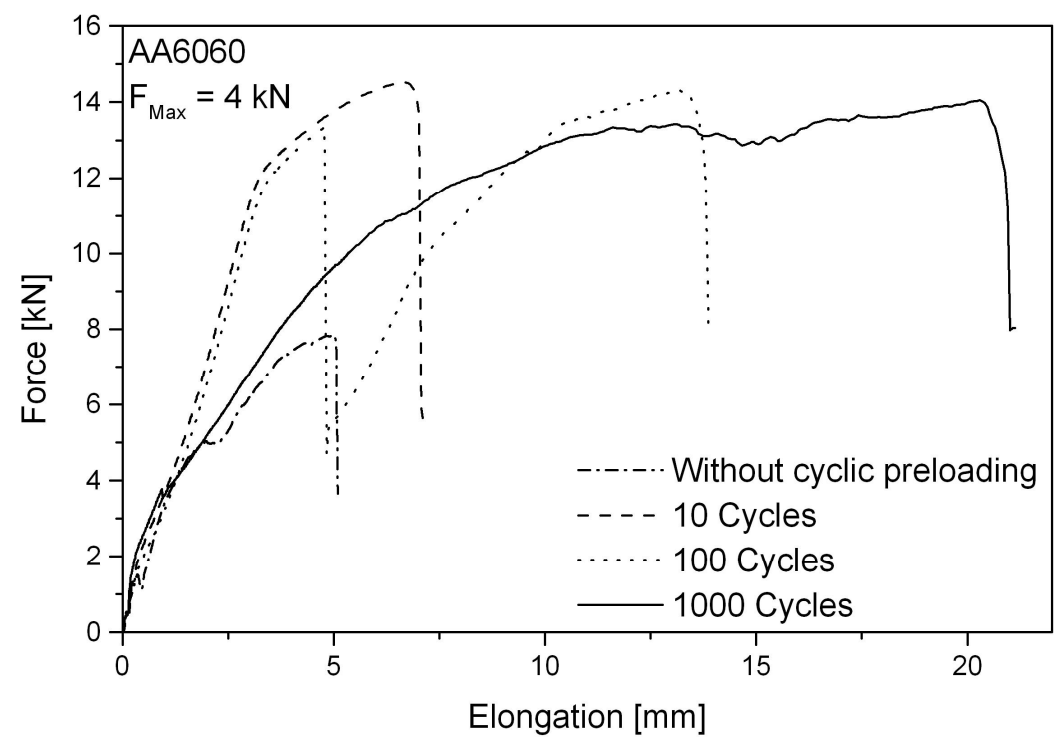

Fig. 7: Force elongation diagrams of cyclically preloaded joints.

A distinct pull-out force cannot be recognized in case of the joint which was preloaded for 10 cycles. The joint can transfer a maximal force of $15.2 \mathrm{kN}$, which corresponds to the tensile strength of the AA6060 tube. In case of a joint which was cyclically preloaded for 100 cycles, a pull-out force of $13.3 \mathrm{kN}$ can be determined. At this point, the force decays drastically because both parts (mandrel and tube) start to glide on each other. After this a "seizing effect" occurs leading to slip between the two components, increasing ploughing effects and therefore to a maximum transferable load of $14.3 \mathrm{kN}$. Finally, the load drops down when both components are completely pulled off. The joint which was cyclically preloaded during 1000 cycles shows a pull-out load of $3.77 \mathrm{kN}$. Subsequently, the seizing effect occurs until the tube is completely pulled out of the mandrel. 
Fig. 8 summarizes the development of the pull-out forces as a function of the maximum force and the number of cycles of preloading.

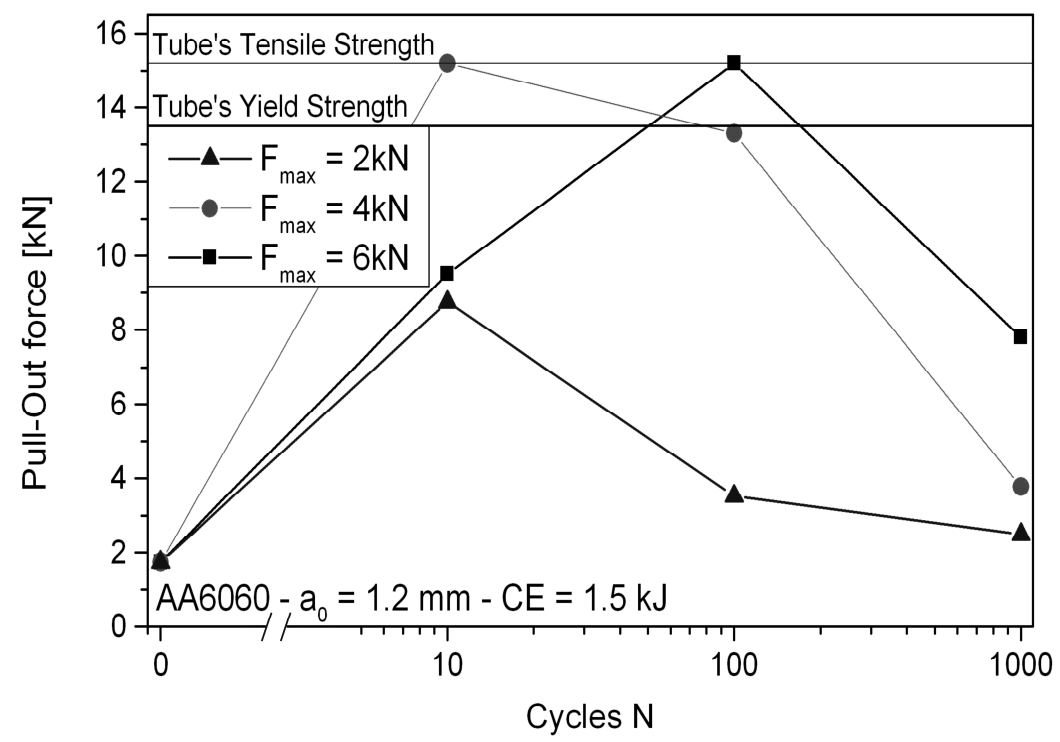

Fig. 8: Dependence of the pull-out load on the maximum force and the number of cycles after preload tests.

At all preload forces investigated, a severe increase of the pull-out force can be achieved. This is most pronounced at 4 or $6 \mathrm{kN}$, where the tube's tensile strength was reached after 10 or 100 cycles, resp. At $2 \mathrm{kN}$ the force seems to be too low in order to achieve a sufficiently high friction welding effect. At all preloading conditions the pull-out force is steeply decreasing at high numbers of cycles of preloading. This may be due to initiaton of fatigue damage. Therefore only a small gap between the positive effect of friction welding and the detrimental effect of damaging during preloading remains.

FSW welds. Fig 9 shows micrographs acquired along the weld seam of specimens welded with rotational speeds of 750,1000, 1200 and $1500 \mathrm{rpm}$, respectively and using a pin with a diameter of $5 \mathrm{~mm}$. All micrographs show cuts through the weld with viewing direction parallel to the pin axis. The weld seam is placed in the middle of the image and the welding direction is from right to left. With respect to the investigated welding parameters, the shape and morphology of the weld zone is parameter dependent. The reinforcement elements can only be observed on the right side of the weld seam (upper part of the images). This means that the reinforcement elements were pushed up on the right side and pulled down on the left side of the weld seam due to the thread contour of the welding pin. Furthermore the reinforcement elements were bended in the welding direction. In addition, steel splitters from the reinforcement elements and holes in the weld seam can be observed. The probability for welding defects decreases by increasing the rotational speed. Holes are hardly observable for a rotation speed of $1500 \mathrm{rpm}$. However the welding zone still shows steel splitters. 

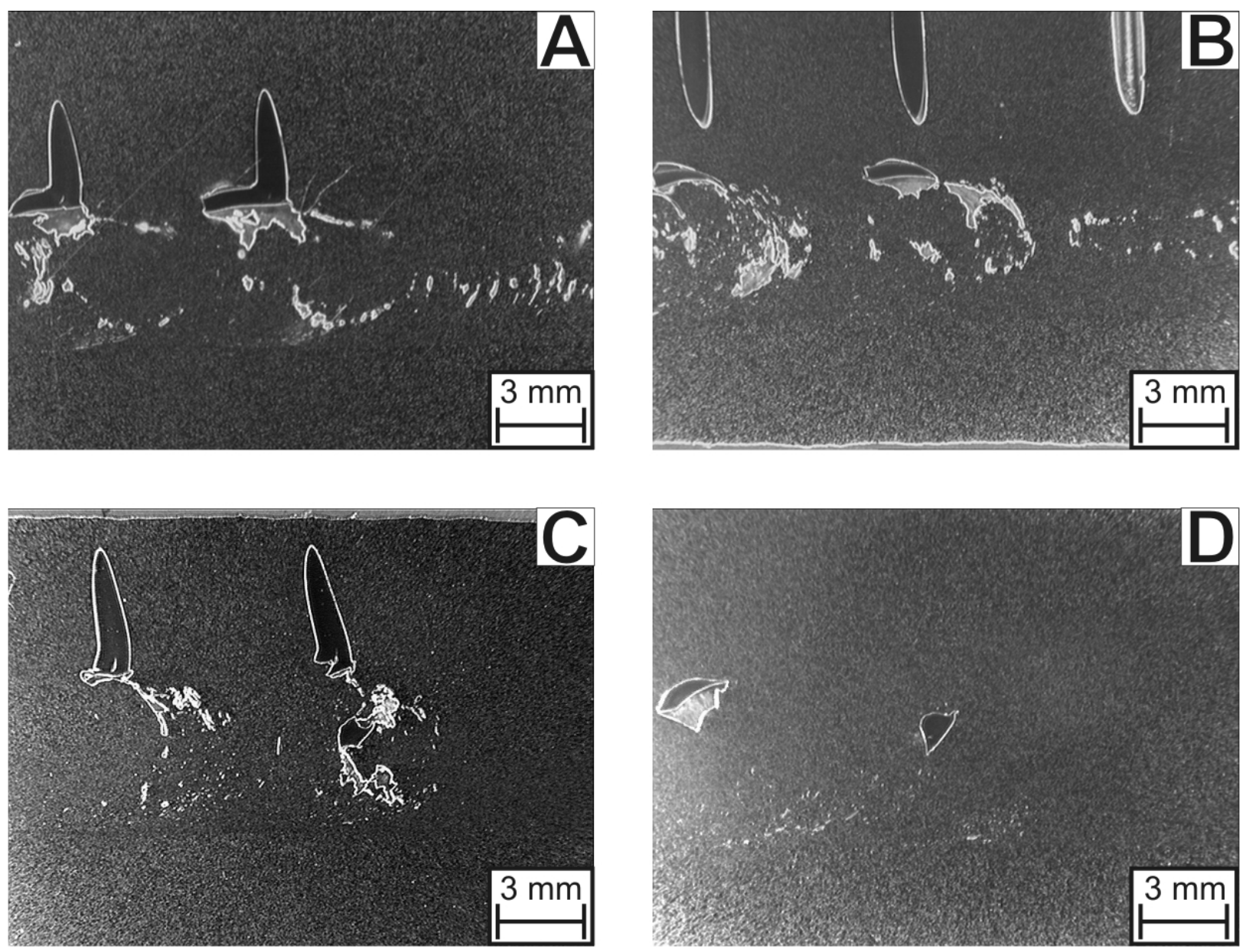

Fig. 9: Microstructure of weld seam welded with different rotational speeds and a $5 \mathrm{~mm}$ long pin. A: $750 \mathrm{rpm}$. B: $1000 \mathrm{rpm}$. C: $1250 \mathrm{rpm}$. D: $1500 \mathrm{rpm}$.

Tensile tests were carried out on several samples welded with all four different rotational speeds. Fig. 10 shows the dependence of the ultimate tensile strength $\mathrm{R}_{\mathrm{m}}$ on the circumferential speed determined from the rotational speed and the pin diameter for the both pin diameters. The achievable $\mathrm{R}_{\mathrm{m}}$ increases with increasing speed. There is a slight increase of the strength at the pin diameter of $5 \mathrm{~mm}$ compared to $4 \mathrm{~mm}$ at low circumferential speeds which vanishes at about 320 $\mathrm{mm} / \mathrm{s}$. Compared to the ultimate tensile strength of the matrix material in the initial T4 state, which was $160 \mathrm{MPa}$ [18] a maximum of $140 \mathrm{MPa}$ is reached. Therefore at high speeds overaging effects may be responsible for the reduced strength. At lower speeds the additional effects of the pores and the splitters of the wire lead to a more severe reduction of the strength. As the larger pin diameter leads to a better circulation of the matrix material at even lower rotational speeds it yields to a slightly higher strength. 


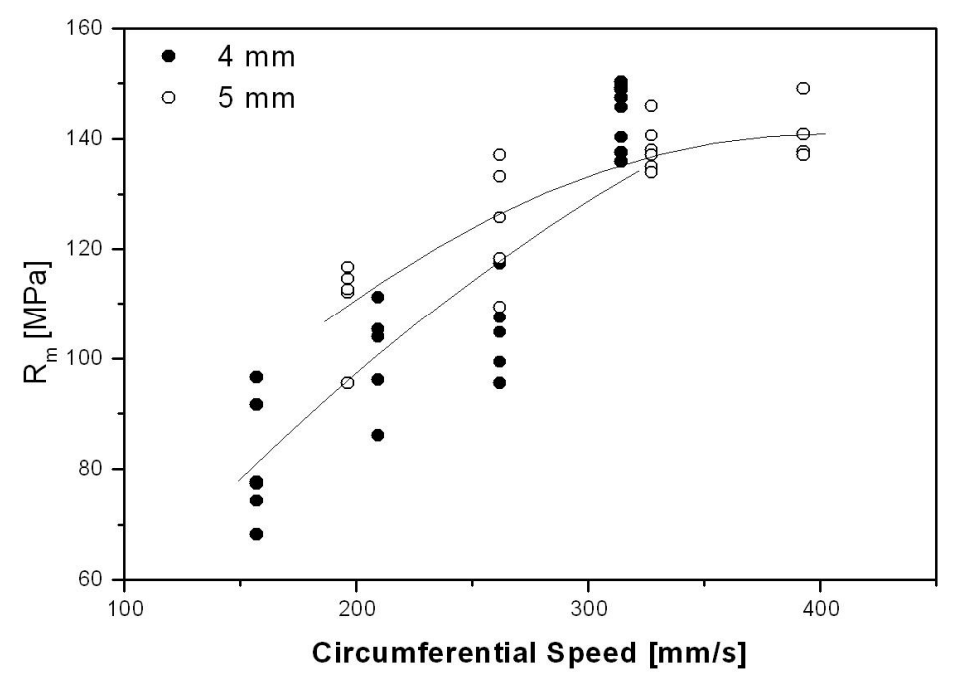

Fig. 10: Dependence of the $\mathrm{R}_{\mathrm{m}}$ on the circumferential speed and the pin diameter.

\section{Conclusions}

Electromagnetic forming. The mechanical properties of joints produced by EMF can be improved with mechanical pre or post welding treatments. The mandrel component can be shot peened in order to improve the achievable pull-out forces. During the shot peening treatment of the mandrel the shot pressure should be as high as possible. The shot media should be square-cut, in order to achieve form fit elements in the contact area between join partners. Joints can also be cyclically preloaded in order to improve the achievable pull-out loads. For this tube and mandrel must be of the same material.

Friction stir welding. In the present work it was shown that friction stir welding gives the possibility to weld reinforced aluminum sheets. Since the microstructure, the presence of defects in the weld seam as well as the strength of welds results improved, welding with high circumferential and speeds seems to be favourable. However, welding imperfections like steel splitters from the reinforcement elements and holes in the weld seam were still found. Further research is needed in this area in order to improve the quality of welded components.

\section{Acknowledgements}

This paper is based on investigations of the Transregional Collaborative Research Centre SFB/TR10, which is kindly supported by the German Research Foundation (DFG).

\section{References}

[1] D. Mamalis, A. Manolakos, A. Kladas, A. Koumoutsos: Electromagnetic forming and powder processing: Trends and developments. Applied Mechanics Reviews (2004) 57, pp. 299-324.

[2] M. Kleiner, C. Beerwald, W. Homberg: Analysis of Process Parameters and Forming Mechanisms within the Electromagnetic Forming Process. CIRP Annals 2005, Vol.1

[3] W. Homberg, M. Marré, M. Kleiner: Umformtechnisches Fügen leichter Tragwerkstrukturen. Aluminium Vol.80 (2004) 12, pp1396-1400. 
[4] F. Bach, M. Rodman, A. Rossberg, J. Weber, L. Walden: Verhalten von Aluminiumwerkstoffen bei der elektromagnetischen Blechumformung. Proc. 2. Kolloq. Elektromagnetische Umformung, 28. Mai 2003, Dortmund, pp. 11-18.

[5] M. Zaeh, D. Eireiner, L. Papadakis: Friction Stir Welding with Modern Milling Machines / Requirements, Approach and Application. Proceedings of the 5th International Friction Stir Welding Symposium, Metz (France), 2004

[6] D. Eireiner: Rührreibschweißen mit Bearbeitungszentrum, in: Maschine + Werkzeug 104, Heft 9 (2005), pp. 56-58

[7] D. Eireiner: Friction stir welding using NC milling machines, in: Welding and Cutting 3 (2004) 4, pp. $220-223$

[8] C. Beerwald: Grundlagen der Prozessauslegung und -gestaltung bei der elektromagnetischen Umformung. Universität Dortmund - IUL, Dr.-Ing. Diss., Reihe Umformtechnik, Shaker Verlag, Aachen 2005, ISBN 3-8322-4421-2.

[9] P. Barreiro, V. Schulze, D. Löhe: Development and Effects of Residual Stresses in Joints Produced by Electromagnetic Compression and its implication on the Mechanical Properties, in: Reimers, W. (ed.), Proc. Europ. Conf. On Residual Stresses 7, Sept. 2006, pp. 485-490

[10] P. Barreiro, V. Schulze, D. Löhe, M. Marré, Ch. Beerwald, W. Homberg, M. Kleiner: Strength of tubular joints made by electromagnetic compression at quasi-static and cyclic loading, in: Kleiner, M. (ed.), Proc. Int. Conf. High Speed Forming, März 2006, pp. 107-116

[11] V. Schulze, P. Barreiro, D. Löhe: Investigation of the Influence of Process Parameters on the Structure and the Mechanical Properties of Joints Produced by Electromagnetic Compression, in: Advanced Materials Research: Flexible Manufacture of Lightweight Frame Structures, Band 10 (2006) pp. 79-88

[12]M. Kleiner, D. Löhe, M. Marré, Ch. Beerwald, P. Barreiro, V. Schulze, W. Homberg: Investigation of force-fit joints produced by electromagnetic tube compression, in: Annals of the German Academic Society for Production Engineering, WGP, Vol. XIII/1 (2006), pp. 227 230

[13] U. Henneböhle, J. Silvanus: FSW-basic-principles and recent trends. In: DVS-Berichte, Band 237 (2005) pp. 498-501

[14]A. Meyer, C. Schilling, A. von Strombeck: Development and series production of multidimensional FSW on industrial components, in: DVS-Berichte * Band 237 (2005) pp. 505-508

[15] S. Kallee, J. Kell, W. Thomas, C. Wiesner: Development and implementation of innovative joining processes in the automotive industry, in: DVS-Berichte * Band 237 (2005) pp. 509-515

[16] L. Cederqvist: A weld that lasts for 100000 years - friction stir welding of copper canisters for spent nuclear fuel, in: DVS-Berichte * Band 237 (2005) pp. 502-504

[17] Information on http://www.msm.cam.ac.uk/phase-trans/2003/FSW/aaa.html

[18]K. A. Weidenmann: Werkstoffsysteme für verbundstranggepresste Aluminiummatrixverbunde, Dissertation an der Universität Karlsruhe (2006), Shaker Verlag Aachen 